\title{
Gynecologic assessment of 19 adult females with cartilage-hair hypoplasia - high rate of HPV positivity
}

\author{
Elina Holopainen ${ }^{1 *}$ (D) Svetlana Vakkilainen ${ }^{2,3}$ and Outi Mäkitie $2,3,4,5$
}

\begin{abstract}
Background: Patients with cartilage-hair hypoplasia $(\mathrm{CHH})$, a rare metaphyseal chondrodysplasia, manifest severe growth failure, variable immunodeficiency and increased risk of malignancies. The impact of $\mathrm{CHH}$ on gynecologic and reproductive health is unknown. Vulnerability to genital infections may predispose $\mathrm{CHH}$ patients to prolonged human papillomavirus (HPV) infections potentially leading to cervical, vaginal and vulvar cancer.

Methods: We carried out gynecologic evaluation, pelvic ultrasound and laboratory assessment in 19 women with genetically confirmed $\mathrm{CHH}$. All patients were clinically examined and retrospective data were collected from hospital records.

Results: The women ranged in age from 19.2 to 70.8 years (median 40.8 years) and in height from 103 to $150 \mathrm{~cm}$ (median $123 \mathrm{~cm}$ ). All women had undergone normal pubertal development as assessed by breast development according to Tanner scale and by age of menarche (mean 12.5 yrs., range 11-14 yrs). Despite significant short stature and potentially small pelvic diameters, a well-developed uterus with fairly normal size and shape was found by pelvic ultrasound in most of the patients. Ovarian follicle reserve, assessed by ultrasound was normal in relation to age in all premenopausal women it could be assessed (12 cases). Anti-Müllerian hormone was normal in relation to age in 17 women (89\%). HPV was detected in $44 \%(8 / 18)$ and three women carried more than one HPV serotype; findings did not associate with immunological parameters. Three patients had a concurrent cell atypia in Pap smear.

Conclusions: Pubertal development, reproductive hormones and ovarian structure and function were usually normal in women with $\mathrm{CHH}$ suggesting fairly normal reproductive health. However, the immunodeficiency characteristic to $\mathrm{CHH}$ may predispose the patients to HPV infections. High prevalence of HPV infections detected in this series highlights the importance of careful gynecologic follow up of these patients.
\end{abstract}

Keywords: Skeletal dysplasia, Contraception, Human papillomavirus, CHH, RMRP

\section{Background}

Cartilage-hair hypoplasia (CHH; MIM \#250250) is a rare autosomal recessive metaphyseal chondrodysplasia with an incidence of 1: 23000 births in Finland [1, 2]. It is characterized by severe short-limbed growth failure (mean adult height for males $131 \mathrm{~cm}$ and for females $123 \mathrm{~cm}$ ), thin and sparse hair, and variable immunodeficiency. The risk of malignancies is sevenfold increased, non-Hodgkin lymphoma being the most common

\footnotetext{
* Correspondence: elina.holopainen@hus.fi

'Women's Hospital, HUS Helsinki University Hospital and University of

Helsinki, P.O. Box 140, FIN-00029 HUS Helsinki, Finland

Full list of author information is available at the end of the article
}

malignancy with a 90-fold incidence compared with normal population [3]. $\mathrm{CHH}$ is caused by biallelic mutations in the noncoding RNA gene, RMRP. RMRP mutations disrupt ribosomal processing and cell cycle, leading to defective cell proliferation [4]. $\mathrm{CHH}$ is highly variable in severity with phenotypic differences also within families.

While major clinical manifestations of $\mathrm{CHH}$ are well-described, almost no data are available on its potential effect on gynecologic and reproductive health and vulnerability to genital infections and HPV-related cancers [2, 5-7]. All these previous studies were based on questionnaires or case reports. None of the previous

(c) The Author(s). 2018 Open Access This article is distributed under the terms of the Creative Commons Attribution 4.0 International License (http://creativecommons.org/licenses/by/4.0/), which permits unrestricted use, distribution, and 
clinical series included gynecologic examination or laboratory evaluation.

Whether fertility is affected in $\mathrm{CHH}$ also remains unclear. In a cohort of 11 adult $\mathrm{CHH}$ males, serum concentrations of testosterone, inhibin $\mathrm{B}$ and gonadotropins were mainly normal. However, semen analyses showed impaired spermatogenesis [8]. Recent case reports have described two $\mathrm{CHH}$ women with hypogonadism [7] and pregnancy outcome of one woman with $\mathrm{CHH}$ [6]. There are no other studies evaluating reproduction in patients with $\mathrm{CHH}$.

This lack of data prompted us to carry out a crosssectional study on gynecologic health in a relatively large cohort of adult women with $\mathrm{CHH}$. We evaluated all subjects clinically and by performing hormonal laboratory measurements and pelvic ultrasound. Pap smear and cervical HPV test were obtained during gynecologic examination.

\section{Patients and methods \\ Patients}

The study protocol was approved by the Institutional Review Board of the Children's Hospital, University of Helsinki and all study participants gave a written informed consent. Patients were identified from the Finnish Skeletal Dysplasia Register which includes $>160$ patients with genetically confirmed $\mathrm{CHH}$. All $R M R P$ mutations had been detected by Sanger sequencing either at Laboratory HUSLAB, Finland, or as a part of previous or ongoing research at Folkhälsan Institute of Genetics, Helsinki [4, 9]. All 55 women aged over 18 years were invited to the study; $19 \mathrm{CHH}$ females agreed, accounting for a participation rate of $34.5 \%$ (Fig.1).

\section{Methods}

Hospital records were reviewed for relevant data. Patients were interviewed for a detailed medical history. Complete gynecologic and pelvic ultrasound examinations (GE Healthcare Voluson S6) were performed by an experienced gynecologist (EH). Pubertal status was recorded according to Tanner's classification [10]. Antral follicle count (AFC) of the ovaries was considered normal if it was between 10th and 90th percentiles of age-specific normal values [11].

Pap smear and cervical HPV test were obtained when anatomically possible. Cervical samples for HPV test were taken by APTIMA cervical collection and transport KIT and HPV subtypes were analyzed by PCR and Luminex suspension array technology [12]. The test detects 15 high-risk HPV types, six potentially high-risk types and 19 low-risk HPV types.

Blood cell count and serum concentrations of sex hormones, prolactin, thyroid stimulating hormone, gonadotropins and Anti-Müllerian hormone (AMH) were measured during clinical visit. Serum estradiol was extracted from serum with diethyl ether and quantitated

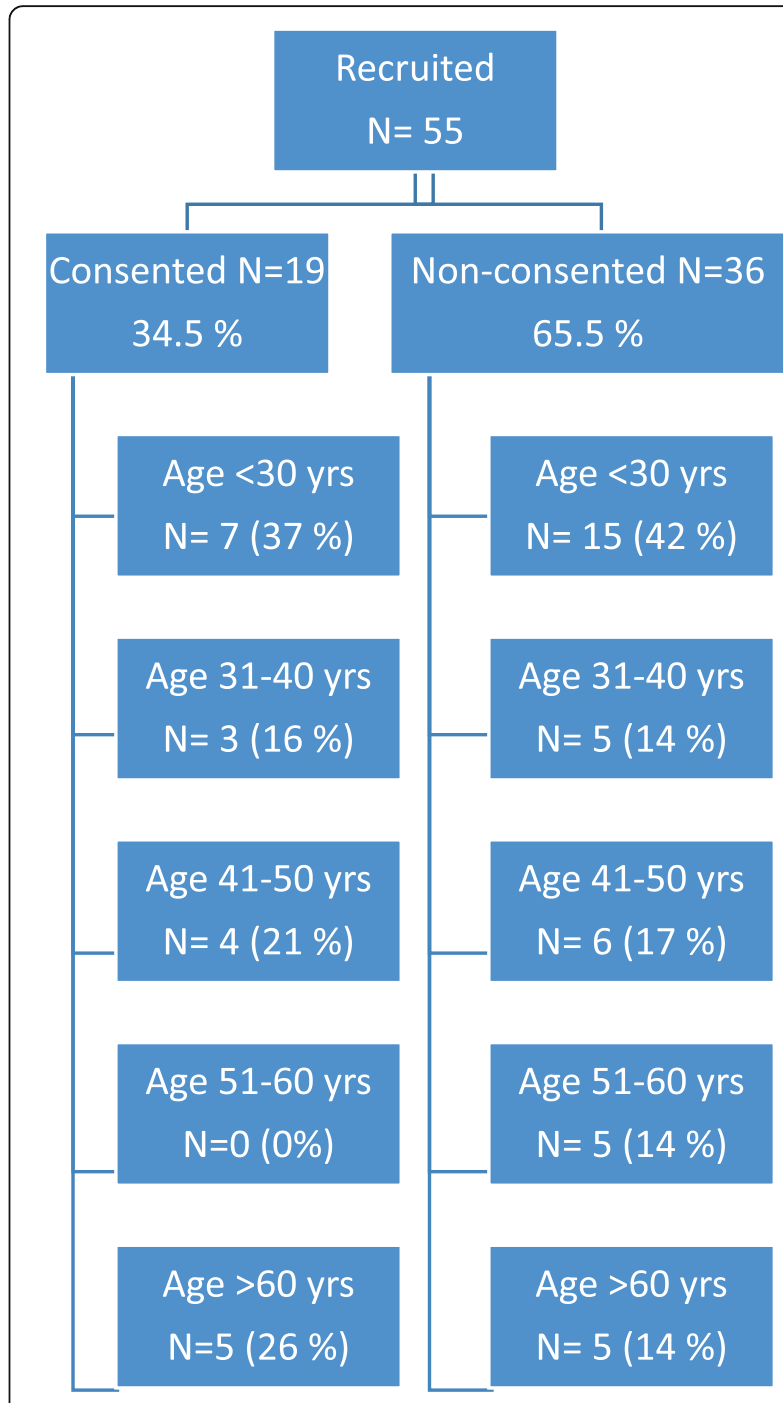

Fig. 1 Flow chart showing the proportions and ages of patients who consented and did not consent to the study

by LC-MS/MS (liquid chromatography-tandem mass spectrometry) using a TQ5500 mass spectrometer (AB Sciex, Concord, Canada). The between-run coefficient of variations (CV \%) were $4.4-5.1 \%$ for serum samples at concentrations $330-900 \mathrm{pmol} / \mathrm{L}$.

Serum luteinizing hormone (LH) and follicle-stimulating hormone (FSH) concentrations were measured using an electrochemiluminescence immunoassay (Abbott Diagnostics, USA). Anti-Müllerian hormone (AMH) was quantitated with an ELISA assay (AMH Gen II ELISA, Beckman Coulter, Brea, CA, USA). Limit of detection (LoD) was $0.08 \mu \mathrm{g} / \mathrm{L}$ and limit of quantitation (LoQ) $0.16 \mu \mathrm{g} / \mathrm{L}$. Intra-assay and inter-assay $\mathrm{CV} \%$ was $<6 \%$ in the range $3.8-16.5 \mu \mathrm{g} / \mathrm{L}$. Total CV \% was $<8 \%$. Age-specific limits of AMH were applied [13]. The method of AMH measuring was changed in the laboratory during the study. In four patients, Anti-Müllerian hormone $(\mathrm{AMH})$ was 
quantitated with an electrochemiluminometric assay on a cobase 411 automatic immunoanalyzer (Elecsys AMH Plus, Roche Diagnostics, Mannheim, Germany). Limit of detection (LoD) was $0.01 \mu \mathrm{g} / \mathrm{L}$ and limit of quantitation (LoQ) $0.03 \mu \mathrm{g} / \mathrm{L}$. Intra-assay $\mathrm{CV} \%$ was $<2 \%$ and inter-assay CV \% was $<5 \%$ in the range $0.2-19 \mu \mathrm{g} / \mathrm{L}$ of AMH. AMH results with this method are 30\% lower than in the ELISA method previously used. For obtaining comparable values by the two different methods, we used mathematical conversion for values detected by Elecsys AMH Plus in four patients ( $1,3 x$ detected value). For plasma levels of immunoglobulins and lymphocyte counts local laboratory reference values were applied as described previously [14].

\section{Statistical analysis}

Standard statistical methods were used as appropriate. Median, mean and/or standard deviation estimates were computed for variables such as age, length and weight. Fisher's exact test and logistic regression analysis were applied to examine the correlations of symptoms and laboratory findings.

\section{Results}

\section{Patient characteristics}

The cohort characteristics are described in Table 1 and clinical and laboratory manifestations of immunodeficiency are shown in Table 2 . The median age of the 19 study participants was 41.8 years (range 19.2-70.8 yrs). All had undergone a normal spontaneous puberty; the median age at menarche was 12.5 years, varying from 11 to 14 years. Five women were regarded postmenopausal, defined by either i) duration of amenorrhea of more than 12 months and FSH $>30$ IU/L (three women) or ii) history of menopausal symptoms and current use of hormonal replacement therapy (two women). Median adult height was $123 \mathrm{~cm}$ $(103-150 \mathrm{~cm})$ and median weight $41.8 \mathrm{~kg}(29.0-80.0 \mathrm{~kg})$. Fifteen patients were homozygous for the $R M R P$ founder mutation c.70A $>\mathrm{G}$ and four patients were compound heterozygous for c.70A $>\mathrm{G}$ and c.262G $>$ T mutations.

\section{Gynecologic status}

All patients had normal breast development, either Tanner stage M4 $(n=1)$ or M5 $(n=18)$. Pubic hair was fully developed (Tanner stage P5, $n=6$ ) or almost fully developed (P4, $n=7)$ in $68 \%$ and partly developed (P3, $n=2)$ or totally absent $(\mathrm{P} 1, n=3)$ in $32 \%$. Those with $\mathrm{P} 1$ had total alopecia.

Pelvic ultrasound examination was performed vaginally in 18 women and abdominally in one woman. In 16 women, the structure of the uterus was considered normal with regard to age, stage of menstrual cycle and the patient's current hormonal therapy (Table 1). Two postmenopausal patients had small, asymptomatic
Table 1 Cohort characteristics

\begin{tabular}{|c|c|}
\hline & $\mathrm{N}$ \\
\hline \multicolumn{2}{|l|}{ Age group (yrs) } \\
\hline $19-30$ & 7 \\
\hline $31-40$ & 3 \\
\hline $41-50$ & 4 \\
\hline $51-60$ & 0 \\
\hline$>60$ & 5 \\
\hline \multicolumn{2}{|l|}{ Height (cm) } \\
\hline$<115$ & 5 \\
\hline $115-130$ & 10 \\
\hline$>130$ & 4 \\
\hline \multicolumn{2}{|l|}{ Reproductive health } \\
\hline Menarche (median, yrs) & 12.5 \\
\hline Cycle length (variation, median, days) & $21-60,28$ \\
\hline \multicolumn{2}{|l|}{ Menstrual flow } \\
\hline sparse & 2 \\
\hline normal & 15 \\
\hline heavy & 2 \\
\hline Pregnancies & $6 / 19$ \\
\hline \multicolumn{2}{|l|}{ Births } \\
\hline 0 & 14 \\
\hline $1-2$ & 1 \\
\hline$>2$ & 4 \\
\hline Current hormonal therapy & $5 / 19$ \\
\hline Combined contraception pills & 1 \\
\hline Progestin only -pills & 2 \\
\hline Hormone replacement therapy & 2 \\
\hline \multicolumn{2}{|l|}{ Immunodeficiency } \\
\hline \multicolumn{2}{|l|}{ Suseptibility to infections ${ }^{a}$} \\
\hline Yes & 9 \\
\hline Intermediate & 4 \\
\hline Normal & 6 \\
\hline \multicolumn{2}{|l|}{ Previous skin warts } \\
\hline Yes & 4 \\
\hline No & 14 \\
\hline Repeated genital infections & $6 / 19$ \\
\hline Previous malignancy ${ }^{\mathrm{b}}$ & 3 \\
\hline Leucocytes $\left(\times 10^{9} / \mathrm{L}\right)$ (range, median) & $3.2-13.4 ; 5.6$ \\
\hline Lymphocytes $\left(\times 10^{9} / \mathrm{L}\right)$ (range, median) & $0.5-2.58 ; 1.22$ \\
\hline Neutrophiles $\left(\times 10^{9} / \mathrm{L}\right)$ (range, median) & $1.74-10.65 ; 3.37$ \\
\hline
\end{tabular}

${ }^{a}$ Yes = one or several episodes of otitis media and/or rhinosinuitits; Intermediate = pneumonia necessitating hospitalization and/or recurrent otitis media and/or rhinosinuitis requiring surgical treatment

b1 squamous cell carcinoma,2 basal cell carcinomas 
Table 2 Clinical and laboratory manifestations of immunodeficiency in 19 patients with cartilage-hair hypoplasia

\begin{tabular}{|c|c|c|c|c|c|c|}
\hline Pt & HPV & $\begin{array}{l}\text { Clinical manifestations of } \\
\text { immunodeficiency }\end{array}$ & $\begin{array}{l}\text { Plasma levels of } \\
\text { immunoglobulins }^{a}\end{array}$ & Lymphocyte counts $^{\mathrm{b}}$ & $\begin{array}{l}\text { Lymphocyte } \\
\text { proliferation }^{c}\end{array}$ & $S A D^{d}$ \\
\hline 2 & + & NA & NA & NA & NA & NA \\
\hline 3 & + & None & Normal & Low TLC, CD3+, CD4+, CD8+, CD19+ & NA & NA \\
\hline 11 & + & $O M, \sin$ & Normal & Low CD19+ & Abnormal & NA \\
\hline 12 & + & $\operatorname{Sin}$ & Normal & Normal & Abnormal & no \\
\hline 13 & + & $\operatorname{Sin}$ & NA & NA & Normal & NA \\
\hline 15 & + & $\mathrm{BE}, \mathrm{Pn}$, Sin requiring surgery & Low lgG & Low CD3+, CD4+, CD19+ & NA & NA \\
\hline 16 & + & $\mathrm{BE}, \mathrm{Pn}, \mathrm{Sin}$ & Normal & Low CD3+, CD4+, CD8+ & Abnormal & yes \\
\hline 17 & + & None & Normal & Low TLC, CD8+ & NA & NA \\
\hline 1 & - & $\mathrm{OM}, \mathrm{Pn}$ & Normal & Low TLC, CD3+, CD4+, CD8+, CD16/56+ & NA & NA \\
\hline 4 & - & $\begin{array}{l}\text { OM, severe varicella requiring } \\
\text { hospitalization }\end{array}$ & Normal & Low TLC, CD3+, CD4+, CD8+, CD19+ & NA & yes \\
\hline 5 & - & OM, Sin & Normal & Low TLC, CD3+, CD4+, CD8+ & Abnormal & NA \\
\hline 6 & - & None & Normal & Low CD3+, CD4+, CD8+, CD19+ & Abnormal & NA \\
\hline 8 & - & $\mathrm{OM}$ & Normal & Normal & Normal & yes \\
\hline 9 & - & Sin requiring surgery & Normal & Low CD19+ & NA & NA \\
\hline 10 & - & $\mathrm{OM}$, Sin requiring surgery & Ig substitution & Low CD3+, CD4+, CD8+, CD19+ & Abnormal & yes \\
\hline 14 & - & $\mathrm{BE}, \mathrm{OM}$, Sin requiring surgery & Normal & Normal & Abnormal & yes \\
\hline 18 & - & $\mathrm{BE}, \mathrm{Pn}$, Sin requiring surgery & Low IgM & Low CD19+ & NA & no \\
\hline 19 & - & None & Normal & Normal & NA & NA \\
\hline 7 & NA & Boils, OM, autoimmunity & Ig substitution & Low TLC, CD3+, CD4+, CD8+, CD19+ & NA & yes \\
\hline
\end{tabular}

$B E$ bronchiectasis, HPV human papillomavirus cervical carriage, $I g$ immunoglobulin, $N A$ data not available, $O M$ recurrent otitis media, $P n$ recurrent pneumonia, $P t$ patient number, SAD specific antibody deficiency, Sin recurrent rhinosinusitis, TLC total lymphocyte count

aLocal laboratory reference values were applied, measured as described previously in (14)

b Local laboratory reference values were applied, measured by flow cytometry as described previously in (14)

'Data were obtained from hospital records, measurement performed by various methods

${ }^{\mathrm{d}} \mathrm{SAD}$ was defined as inadequate antibody response to Pneumovax ${ }^{\circledast}$ : a fourfold rise in antibody titers and post-immunization antibody levels $\geq 0.35 \mu \mathrm{g} / \mathrm{ml}$ to $<70 \%$ of serotypes, measured as described previously in (14)

leiomyomas and one postmenopausal woman had thickened endometrium $(4.8-6.3 \mathrm{~mm})$ during continuous hormone replacement therapy.

Median uterine width, determined as the maximum anterior-posterior distance measured in the mid portion of uterine body on a sagittal view, was $27 \mathrm{~mm}$ (range 20-38 $\mathrm{mm}$ ) and median length of uterine corpus, measured from the fundus to the internal orifice of the uterus on a sagittal view, was $38 \mathrm{~mm}$ (range $26-70 \mathrm{~mm}$ ). The 41-year old woman with the smallest, pre-pubertal-size uterus (anterior-posterior measurement $20 \mathrm{~mm}$, corpus length $26 \mathrm{~mm}$ ) had undergone spontaneous menarche at the age of 11 years, used currently progestin-only pills and had sparse menstrual flow. She had never tried to become pregnant. Another pre-menopausal 46-year old woman also had a relatively small uterus, with corpus anterior-posterior measurement of $20 \mathrm{~mm}$ and corpus length of $29 \mathrm{~mm}$. However, she had used levonorgestrel-releasing intrauterine device for years suggesting fairly normal uterine cavity. In all other pre-menopausal women corpus anterior-posterior measurement was $>25 \mathrm{~mm}$ and corpus length $>30 \mathrm{~mm}$.
The structure of ovaries could be assessed in 16/19 subjects and all were considered normal in relation to age, phase of menstrual cycle and use of hormonal therapy. In three postmenopausal women (aged 60-70 years) ovaries could not be identified.

AFC in both ovaries could be assessed in 12 premenopausal women and was normal in all. In two cases, AFC from only one ovary could be reliably counted (Table 3).

\section{Laboratory parameters}

Blood cell count was analyzed in 18/19 cases. Mean hemoglobin was $131 \mathrm{~g} / \mathrm{L}$ (range 111-146 g/L). Only one woman had hemoglobin under normal range $(111 \mathrm{~g} / \mathrm{L}$, normal values 117-155 g/l). Mean white blood cell count was $6.3 \times \mathrm{x} \mathrm{e}^{9} / \mathrm{L}$ (range 3.2-13.4 $\mathrm{x} \mathrm{e}^{9} / \mathrm{L}$ ) and platelet count $275 \times \mathrm{e}^{9} / \mathrm{L}$ (range $147-398 \times \mathrm{e}^{9} / \mathrm{L}$ ).

AMH was measured from all 19 patients and was under detection limit in all postmenopausal women $(n=5)$ and in the two perimenopausal women (aged > $45 \mathrm{yrs}$ ). Most of the premenopausal women had normal $\mathrm{AMH}$ according to age-specific reference values (Table 3). Two women had lower than expected AMH levels and 
Table 3 Antral follicle count and hormone levels in 14 premenopausal women with cartilage-hair hypoplasia

\begin{tabular}{|c|c|c|c|c|c|c|c|c|}
\hline Study subject & Age group & Current hormonal treatment & Day of menstrual cycle & AFC $(N)$ & FSH (IU/L) & LH (IU/L) & E2 (nmol/L) & $\mathrm{AMH}(\mathrm{ug} / \mathrm{L})$ \\
\hline 1 & $19-30$ & CC & - & 18 & 3.7 & 2.3 & 0.179 & 1.97 \\
\hline 2 & $19-30$ & & 9 & 12 & 5 & 3.8 & 0.643 & 0.94 \\
\hline 3 & $19-30$ & & 14 & 15 & 14 & 25.2 & 0.434 & 2.29 \\
\hline 4 & $19-30$ & & 26 & 18 & 5.7 & 7.2 & 0.316 & 4.66 \\
\hline 5 & $19-30$ & PP & - & $7^{\mathrm{a}}$ & 7.3 & 4.9 & 0.07 & 3.68 \\
\hline 6 & $19-30$ & & 14 & 10 & 2 & 0.9 & 0.264 & 1.87 \\
\hline 7 & $19-30$ & & 20 & 16 & 1.8 & 0.6 & 0.49 & 1.39 \\
\hline 8 & $31-40$ & & 5 & 14 & 5.6 & 4.9 & 0.32 & 5.68 \\
\hline 9 & $31-40$ & & 17 & 10 & 6 & 12.5 & 0.579 & $<0.2$ \\
\hline 10 & $31-40$ & & 19 & $3^{\mathrm{a}}$ & 2.7 & 1.6 & 0.423 & 0.63 \\
\hline 11 & $41-50$ & PP & - & 4 & 5 & 1.6 & 0.081 & 0.22 \\
\hline 12 & $41-50$ & & 20 & 9 & 3.1 & 3.8 & 0.336 & 1.34 \\
\hline 13 & $41-50$ & & t.a., am & 5 & 8.5 & 4.8 & 0.231 & $<0.2$ \\
\hline 14 & $41-50$ & & $4 \mathrm{mo}$ am & 1 & 68.4 & 40.9 & 0.046 & $<0.2$ \\
\hline
\end{tabular}

AFC antral follicle count, $A M H$ anti-Müllerian hormone, CC combined contraception, E2 estradiol, FSH follicle-stimulating hormone, $L H$ luteinizing hormone, mo months, $N$ number, $P P$ progestin-only pill, am amenorrhea; t.a. endometrium thermoablation done; 'a Detected from one ovary only. Numbers in bold represent values below normal age-specific values and numbers in italics low normal age-specific values. AMH values detected by two different methods are converted mathematically to correspond each other as described in detail in Methods. Ages are given as age groups to ensure anonymity

there was a discrepancy between the age-specific AMH level and AFC detected by vaginal ultrasound. The first one (patient \#2, Table 3) was a young woman with normal AFC (12) while AMH of $0.94 \mu \mathrm{g} / \mathrm{L}$ suggested lower ovarian reserve. The other patient (patient \# 9, Table 3) had normal AFC (10), but AMH was under detection level $(<0.2 \mu \mathrm{g} / \mathrm{L})$. Both had regular cycles (period 28) and did not use hormonal therapy. One patient had low-normal level of AMH with normal AFC (patient \# 7, Table 3). In none of the patients both AFC and AMH suggested lower than normal age-specific ovarian reserve.

FSH, LH and estradiol levels were consistent with the phase of cycle or use of hormone treatment (Table 3). Thyroid stimulating hormone and testosterone levels were all in normal range.
Prolactin level was increased in two women $(2460 \mathrm{mU} / \mathrm{L}$ and $588 \mathrm{mU} / \mathrm{L}$; normal range $50-500 \mathrm{mU} / \mathrm{L}$ ), both women were on psychiatric medication affecting prolactin secretion.

\section{Pap smear and HPV-tests}

Pap smear and cervical HPV test were obtained from 18/19 cases. Altogether 9 women had abnormal findings; these are presented in Table 4. Eight of the 18 women (44\%) had a positive HPV test. Five were positive for one subtype, three of which were of high-risk types. Another two women had two high-risk subtypes. Finally, one woman tested positive for three different HPV subtypes, one of which was classified as a high-risk type. We found no correlation between the HPV status and any other clinical manifestations of immunodeficiency or

Table 4 Abnormal Pap smear and human papilloma virus test results in nine women with cartilage-hair hypoplasia. Ages are given as age groups to ensure anonymity

\begin{tabular}{|c|c|c|c|c|c|c|}
\hline Study subject & Age group & Previous abnormal Pap smear & Current Pap smear & Positive HPV test & HPV types & High-risk HPV type \\
\hline 1 & $19-30$ & NA & ASC-US & - & - & - \\
\hline 2 & $19-30$ & NA & ASC-US & + & 42 & No \\
\hline 3 & $19-30$ & Yes & LSIL & + & $56,(66,67)$ & Yes \\
\hline 11 & $41-50$ & Yes & Normal & + & 16 & Yes \\
\hline 12 & $41-50$ & Yes & ASC-US & + & 52,59 & Yes \\
\hline 13 & $41-50$ & No & Normal & + & 56 & Yes \\
\hline 15 & $>60$ & No & Normal & + & 30 & No \\
\hline 16 & $>60$ & No & Normal & + & 74 & No \\
\hline 17 & $>60$ & No & Normal & + & 16,18 & Yes \\
\hline
\end{tabular}


previously measured blood lymphocyte subset counts or serum immunoglobulin levels (Table 2). All patients with high-risk HPV had recently undergone thorough immunologic evaluation with normal counts of $T$ and $B$ cells and normal immunoglobulin A, M and G levels.

\section{Discussion}

Little is known about gynecologic health in women with $\mathrm{CHH}$ and our study provides important novel data that can be implemented in the management and follow-up of patients with $\mathrm{CHH}$ and increase our knowledge on gynecological issues more widely among women with skeletal dysplasia. The main findings of our study include normal pubertal development, mostly normal genital anatomy and a high prevalence of HPV positivity.

We have previously described two young $\mathrm{CHH}$ women with absent spontaneous pubertal development and reduced ovarian reserve [7]. However, in this study consisting of 19 women with $\mathrm{CHH}$ and severe disproportional growth failure, pubertal development and sexual maturation were normal as assessed by Tanner scale and age of menarche. Further, the size of uterus was within normal range in $18 / 19$ women. In one woman, at age 41 years, the size of uterus resembled pre-pubertal uterus $[15,16]$. However, she had a spontaneous menarche and history of regular cycles suggesting fairly normal estrogen production. It remains unknown whether the small uterus is due to direct effects of aberrant $R M R P$ function or mediated by e.g. endocrine factors. AFC was normal in relation to age in all those who could be evaluated, suggesting fairly normal fertility potential in this patient group. The lack of pubarche in three patients is likely to be a result from impaired germ-cell proliferation in the hair follicles.

For practical reasons blood tests for hormonal measurements were taken during clinical appointment. Three women were on hormonal contraception at that time. Combined contraception may decrease the level of $\mathrm{AMH}$ and number of AFC resulting in underestimation of fertility potential $[17,18]$. However, in a woman using combined contraception in our series, AMH and AFC were normal. In two other patients, progestin only pills were used. Their effect on hormonal levels is less evident than that of combined contraception [17].

Sexually active $\mathrm{CHH}$ women are at risk for acquiring HPV and combined immunodeficiency may predispose them to prolonged or severe infection. A Finnish series of women attending HPV screening during 2003-2005 showed age -specific HPV positivity to vary from 2.8$24.2 \%$ in women aged 25-65 years [19]. In our series one or more HPV subtypes were found in $44 \%(8 / 18)$ patients with $\mathrm{CHH}$. Two of our patients with HPV were under 25 years of age, and the prevalence in this age-group is known to be higher [20]. However, spontaneous recovery of HPV infection is more common in the young age group. Five of those with HPV $(62.5 \%, 5 / 8)$ had high-risk HPV subtypes. In the Finnish population, high-risk subtypes have been found in 41.2-65.3\% of HPV positive screening samples [19]. Since prolonged infections with high-risk HPV subtypes predispose to cervical cancer, careful and systematic follow-up of abnormal Pap smears is of utmost importance in immune deficient $\mathrm{CHH}$ patients. Also, HPV vaccination should be considered. In our patients with high-risk HPV carriage, normal lymphocyte subsets and immunoglobulin levels have been documented previously, highlighting the importance of screening also $\mathrm{CHH}$ patients with subclinical immunodeficiency.

Most of the $\mathrm{CHH}$ women in our series were or had been sexually active, indicating a need for reliable and suitable contraception. In a previous study, intrauterine device (IUD) was used only by $8 \%$ of short-statured women [5]. This may be explained by fear of potential difficulties or complications in IUD insertion caused by disproportionate pelvic diameters and the fact that Copper IUD can exacerbate menstrual cramps and menstrual flow. However, nowadays, levonorgestrel releasing IUD is an effective contraceptive method treating also heavy menstruation. Based on the possibility of performing clinical gynecologic examination and the normal uterine measurements found in the present study, we regard the use of levonorgestrel releasing IUD a valuable option for women with $\mathrm{CHH}$. By reducing menstrual flow, it may also have a positive effect on potential anemia due to bone marrow failure, a possible complication in $\mathrm{CHH}$.

Our study is limited due to the relatively small size of the cohort and the low participation rate which may cause bias. However, in rare diseases larger cohorts are often impossible to obtain. In $\mathrm{CHH}$, severe short stature further complicates participation of individuals living far from the study center. The participation rate was comparable to our previous studies on $\mathrm{CHH}$. Further, our study permit did not allow us to collect data on the offspring's health, including postnatal growth. Despite these limitations our study is the largest gynecological evaluation ever performed in $\mathrm{CHH}$ or any other skeletal dysplasia and thus provides valuable new data. Further studies are needed to further elucidate the largely unknown field of gynecological health in women with skeletal dysplasia and the outcomes of their pregnancies.

\section{Conclusions}

Immunodeficiency and increased risk for malignancies contribute to significant morbidity in $\mathrm{CHH}$ patients. While major clinical manifestations of $\mathrm{CHH}$ are well-described, only little is known about gynecologic health in $\mathrm{CHH}$. In this prospective series reproductive 
hormones and health were fairly normal. However, high prevalence of HPV infections detected in this series highlights the importance of careful gynecologic follow up of these patients since immunodeficiency may predispose $\mathrm{CHH}$ patients to HPV infections.

\section{Abbreviations}

AFC: Antral follicle count; AMH: Anti-Müllerian hormone; $\mathrm{CHH}$ : Cartilage-hair hypoplasia; CV: Coefficient of variation; FSH: Follicle-stimulating hormone; HPV: Human papillomavirus; LH: Luteinizing hormone; LoD: Limit of detection; LoQ: Limit of quantification

\section{Acknowledgments}

The authors would like to thank research nurse Nea Boman for her excellent help in contacting the patients and organizing appointments.

\section{Funding}

This study was supported by the Sigrid Jusélius Foundation; the Academy of Finland; the Folkhälsan Research Foundation; the Helsinki University Hospital Research Funds; the Doctoral School in Health Sciences at the University of Helsinki and the Foundation for Pediatric Research.

\section{Availability of data and materials}

All data generated or analysed during this study are included in the published article.

\section{Authors' contributions}

EH, SV and OM conceived the study and reviewed the literature. EH performed gynecologic examination and analysed the results. EH, SV and OM prepared the manuscript. All authors critically revised the manuscript and approved the final version.

\section{Ethics approval and consent to participate}

The study protocol was approved by the Institutional Review Board of the Children's Hospital, University of Helsinki and all study participants gave a written informed consent.

\section{Consent for publication}

Consents for publication were received from people participating in the study (written informed consent). Individual patients cannot be identified from the data shown.

\section{Competing interests}

The authors declare that they have no competing interests.

\section{Publisher's Note}

Springer Nature remains neutral with regard to jurisdictional claims in published maps and institutional affiliations.

\begin{abstract}
Author details
'Women's Hospital, HUS Helsinki University Hospital and University of Helsinki, P.O. Box 140, FIN-00029 HUS Helsinki, Finland. ${ }^{2}$ Children's Hospital, Pediatric Research Center, HUS Helsinki University Hospital and University of Helsinki, Helsinki, Finland. ${ }^{3}$ Institute of Genetics, Folkhälsan Research Center, Helsinki, Finland. ${ }^{4}$ Department of Molecular Medicine and Surgery, Karolinska Institutet, Stockholm, Sweden. ${ }^{5}$ Department of Clinical Genetics, Karolinska University Hospital, Stockholm, Sweden.
\end{abstract}

Received: 11 July 2018 Accepted: 30 October 2018 Published online: 16 November 2018

\section{References}

1. Mäkitie O. Cartilage-hair hypoplasia in Finland: epidemiological and genetic aspects of 107 patients. J Med Gen. 1992;29:652-5.

2. Mäkitie O, Kaitila I. Cartilage-hair hypoplasia: clinical manifestations in 108 Finnish patients. Eur J Pediatr. 1993;152:211-7.

3. Taskinen M, Ranki A, Pukkala E, Jeskanen L, Kaitila I, Mäkitie O. Extended follow-up of the Finnish cartilage-hair hypoplasia cohort confirms high incidence of non-Hodgin lymphoma and basal-cell carcinoma. Am J Med Genet A. 2008;146A:2370-5.

4. Ridanpää M, Sistonen P, Rockas S, Rimoin DL, Mäkitie O, Kaitila I. Worldwide mutation spectrum in cartilage-hair hypoplaisa. Ancient founder origin of the major $70 \mathrm{~A} \rightarrow \mathrm{G}$ mutation of the untranslated RMRP. Eur J Hum Gen. 2002:10:439-47.

5. Allanson JE, Hall JG. Obstetric and gynecologic problems in women with chondrodystrophies. Obstet Gynecol. 1986;67:74-8.

6. Thavarajah $\mathrm{H}$, Berndl A. Pregnancy outcome in cartilage-hair hypoplasia, a rare form of dwarfism. Case reports in Obstetr Gynecol. 2017. https://doi. org/10.1155/4737818.

7. Holopainen E, Vakkilainen S, Mäkitie O. Diversity of pubertal development in cartilage-hair hypoplasia - two illusatrative cases. J Pediatr Adolesc Gynecol. 2018;31:422-5.

8. Mäkitie OM, Tapanainen PJ, Dunkel L, Siimes M. Impaired spermatogenesis: an unrecognized feature of cartilage-hair hypoplasia. Ann Med. 2001;33:201-5.

9. Kostjukovits S, Degerman PM, Klemetti P, Landfors M, Roos G, et al. Decreased telomere length in children with cartilage-hair hypoplasia. J Med Gen. 2017:54:365-70.

10. Tanner JM. Growth at adolescence. 2nd ed. Oxford: Blackwell Scientific Publications; 1962.

11. Bozdag G, Calis P, Zengin D, Tanacan A, Karahan S. Age related nomogram for antral follicle count in general population and comparison with previous studies. Eur J Obstet Gynecol Repord Biol. 2016;206:120-4.

12. Schmitt M, Bravo IG, Snijders PJ, Gissmann L, Pawlita M, Waterboer T. Beadbased multiplex genotyping of human paillomaviruses. J Clin Microbiol. 2006:44:504-12.

13. Anckaert E, Öktem M, Thies A, Cohen-Barcie M, Daan NM, Schiettecatte J, et al. Muticenter analytical performance evaluation of a fully automated anti-Müllerian hormone assay and reference intervaldetermination. Clin Biochem. 2016:49:260-7.

14. Kostjukovits S, Klemetti P, Valta H, Martelius T, Notarangelo LD, Seppänen M, Taskinen M, Mäkitie O. Analysis of clinical and immunologic phenotype in a large cohort of children and adults with cartilage-hair hypoplasia. J Allergy Clin Immunol. 2017;140:612-4.

15. Asavoaie C, Fufezan O, Cosarca M. Ovarian and uterine ultrasonography in pediatric patients. Pictorial essay. Med Ultrasound. 2014;16:160-7.

16. Badouraki M, Christoforidis A, Economou I, Dimitriadis AS, Katzos G. Evaluation of pelvic ultrasonography in the diagnosis and differentiation of various forms of sexual precocity in girls. Ultrasound Obstet Gynecol. 2008;32:819-27.

17. Kallio S, Puurunen J, Ruokonen A, Vaskivuo T, Piltonen T, Tapanainen JS. AntiMüllerian hormone levels decrease in women using combined contraception independently of administration route. Fertil Steril. 2013;99:1305-10

18. D'Arpe S, DiFeliciantonio M, Candelieri M, Franceschetti S, Piciconi MG, Bastianelli C. Ovarian function during hormonal contraception assessed by endocrine and sonographic markers; a systematic review. Reprod BioMed Online. 2016;33:436-48.

19. Leinonen M, Anttila A, Malila N, Forslund O, Dillner J, Nieminen P. Type- and age-specific distribution of human papillomavirus in women attending cervical cancer screening in Finland. Brit J Cancer. 2013;109:2941-50.

20. Molden T, Feiring B, Ambur OH, Christiansen IK, Hansen M, Laake I, et al. Human papillomavirus prevalence and type distribution in urine samples from Norwegian women aged 17 and 21 years: a nationwide crosssectional study of three non-vaccinated birth cohorts. Papillomavirus Res. 2016:2:153-8.

\section{Ready to submit your research? Choose BMC and benefit from:}

- fast, convenient online submission

- thorough peer review by experienced researchers in your field

- rapid publication on acceptance

- support for research data, including large and complex data types

- gold Open Access which fosters wider collaboration and increased citations

- maximum visibility for your research: over $100 \mathrm{M}$ website views per year

At BMC, research is always in progress.

Learn more biomedcentral.com/submission 